\title{
Sistem Informasi Akademik Menggunakan CI (CodeIgniter) pada Yayasan Az zahra Tangerang Selatan
}

\author{
Arfan Sansprayada ${ }^{* 1)}$, Kartika Mariskhana ${ }^{2)}$, Riva Abdillah Aziz ${ }^{3)}$ \\ ${ }^{1) 2}$ Universitas Bina sarana Informatika \\ ${ }^{3}$ STMIK Nusa Mandiri \\ ${ }^{*}$ Correspondence Author: arfan.anp@ @si.ac.id, DKI Jakarta, Indonesia \\ DOI: https://doi.org/10.37012/jtik.v6i2.211
}

\begin{abstract}
Abstrak
Perkembangan teknologi merupakan salah satu cara untuk menjalankan suatu proses atau teknologi agar dapat berjalan dengan baik dan benar. Penerapan tersebut dapat dilakukan dengan berbagai cara salah satunya adalah pengembangan dalam implementasi aplikasi. Yayasan aZ Zahra merupakan salah satu yayasan yang bergerak dibidang pendidikan, terdiri dari TK,SD Serta SMU. Untuk menunjang proses belajar mengajar baik dari guru ataupun ke siswa maka dibutuhkan suatu implementasi sistem yang baik agar proses belajar dan mengajar dapat terlaksana dengan baik dan benar. Dengan implementasi ini memberikan kemudahan kepada Yayasan Az Zahra agar dapat memonitoring semua kegiatan akademik serta proses belajar dan mengajar baik tingkat TK, SD ataupun tingkat SMU.
\end{abstract}

Kata Kunci: Sistem Informasi, Akademik, CodeIgniter

\begin{abstract}
Technological development is one way to run a process or technology in order to run well and correctly. The application can be done in various ways one of which is the development in application implementation. Az Zahra Foundation is one of the foundations engaged in education, which consists of kindergarten, elementary school and high school. To support the teaching and learning process both from the teacher or to the students, a good system implementation is needed so that the learning and teaching process can be carried out properly and correctly. This implementation will make it easier for the Az Zahra Foundation to be able to monitor all academic activities and teaching and learning processes at the kindergarten, elementary or high school level.
\end{abstract}

Keywords: Information Systems, Academic CodeIgniter

\section{PENDAHULUAN}

Dengan sangat pesatnya perkembangan teknologi saat ini, banyak pihak yang memanfaatkan kesempatan ini untuk membuat sistem informasi yang dapat membantu efektifitas dan efisiensi suatu aktifitas. Menurut Indrayasa (2015) memberikan batasan bahwa : Sistem adalah suatu jaringan kerja dari prosedur-prosedur yang saling berhubungan, berkumpul bersama-sama untuk melakukan suatu kegiatan atau untuk menyelesaikan suatu sasaran tertentu atau merupakan kumpulan dari elemen-elemen yang saling berinteraksi untuk mencapai tujuan tersebut. Sedangkan informasi adalah data yang diolah menjadi bahan yang lebih berguna dan berarti bagi penerimanya.

Demikian juga dalam dunia pendidikan, informasi adalah suatu hal yang sangat penting. Informasi yang diberikan haruslah akurat, penting dan tidak boleh salah sehingga tidak menimbulkan mis-interpretasi atau kesalahpahaman. 
Saat ini Perguruan Yayasan Pendidikan Az zahra masih menggunakan sistem informasi yang bersifat konvensional dan semi manual sehingga sering terjadi kesalahan dalam penyampaian dan penerimaan informasi serta masih didapatkan ada siswa yang terlambat dalam mendapatkan informasi yang disampaikan oleh pihak yayasan dan pada akhirnya ini menyebabkan kesalahpahaman dalam menyerap informasi.

Untuk mengatasi masalah tersebut, diperlukan suatu sistem informasi yang cepat dan tepat yang dapat dikelola dengan mudah. Yaitu suatu sistem yang memanfaatkan perkembangan teknologi. Penelitian ini bertujuan membuat suatu sistem informasi akademik berbasis website yang dapat menyampaikan informasi lebih efektif dan efisien. Selain lebih efektif, sistem informasi akademik berbasis web dengan menggunakan framework CI (CodeIgniter) dinilai lebih cepat dan tepat dalam penyampaian informasi.

\section{METODE}

Teknik pengumpulan data penelitian menggunakan beberapa teknik yaitu :

1. Observasi

Penulis melakukan obervasi ke Yayasan Az zahra, melihat banyaknya siswa/i yang menuntut ilmu disana dan melihat sistem serta media penyampaian informasi yang di gunakan.

\section{Interview}

Sebelum pembuatan sistem ini, penulis juga melakukan wawancara dengan Bapak Abdurrahman, salah satu staff administrasi yang bekerja di Yayasan Az Zahra. Saat ini Yayasan membutuhkan suatu sistem yang dapat membantu untuk menyampaikan suatu informasi dengan cepat, tepat dan mudah dan tidak terlalu banyak mengeluarkan biaya.

\section{Studi Pustaka}

Studi pustaka yang dilakukan yaitu dengan mengumpulkan data yang berhubungan dengan pembuatan website, penulis juga mengumpulkan data yang berhubungan dengan sistem informasi dan teknologi website saat ini melalui buku maupun internet.

Model pengembangan sistem menggunakan beberapa langkah yaitu :

1. Analisa Kebutuhan Sistem

Dalam pengembangan sistem dilakukan beberapa tahapan dalam menganalisa kebutuhan software. merencanakan penggunaan software yang tepat yang dapat menunjang pembuatan sistem informasi akademik berbasis website.

2. Desain 
Tampilan antarmuka yang disajikan untuk pengguna yang ada pada website adalah terdapat tombol menu, header, form login, content yang terdiri dari beberapa kolom yang berfungsi untuk memuat informasi, serta footer. Software yang digunakan untuk membuat dan merancang desain dalam pembuatan sistem informasi akademik berbasis website menggunakan phpMyAdmin di dalam web server XAMPP.

3. Code Generation

Bahasa pemrograman yang digunakan untuk pembuatan sistem informasi akademik adalah Hyper Text Markup Language (HTML) dan Hypertext Preprocessor (PHP) dengan menggunakan metode pemrograman terstruktur atau prosedural pengolah bahasa pemrograman yang digunakan oleh penulis untuk membuat sistem informasi akademik ini adalah Adobe Dreamweaver CS6..

4. Testing

Sistem informasi akademik berbasis website ini akan di uji / testing dengan 2 tahap pengujian, yang pertama melalui pengujian white box dimana sebagian tahap pengujian ini meliputi pengujian algoritma yang dibuat, baik pengujian secara sebagian ataupun secara keseluruhan. Dan yang kedua adalah melalui pengujian black box yaitu pengujian input-output apakah input menghasilkan output yang sesuai diharapkan atau tidak.

5. Support

Sistem informasi akademik berbasis website ini dibangun dengan aplikasi pengolah bahasa pemprograman yaitu Adobe Dreamweaver CS6 dengan system operasi windows 7. Dan didukung dengan hardware berupa prosesor core i7, memory 4GB dengan hardisk 1TB.

Menurut (Hamim Tohari, 2014 : 2), "Sistem adalah kumpulan atau himpunan dari unsur atau variabel-variabel yang saling terkait, saling berinteraksi, dan saling tergantung satu sama lain untuk mencapai tujuan”. Selain itu sistem juga dapat didefinisikan sebagai "sekumpulan objek-objek yang saling berelasi dan berinteraksi, serta hubungan antar objek dilihat sebagai satu kesatuan yang dirancang untuk mencapai satu tujuan yang telah ditetapkan". Menurut kadir didalam (2014:61) "Sistem adalah sekumpulan elemen yang saling terkait atau terpadu yang dimaksudkan untuk mencapai suatu tujuan”.

Menurut Gordon B Davis (2015:8) "Informasi adalah data yang telah diolah menjadi suatu bentuk yang penting bagi si penerima dan mempunyai nilai nyata yang dapat dirasakan dalam keputusan-keputusan yang sekarang atau keputusan-keputusan yang akan datang. 
Menurut Alter dalam Kadir (2014:9) "Sistem informasi adalah kombinasi antara prosedur kerja, informasi, orang, dan teknologi informasi yang diorganisasikan untuk mencapai tujuan dalam sebuah organisasi".

Menurut Sukamto dan Shalahuddin (2013:133) UML (unified modeling language) yaitu standarisasi bahasa pemodelan untuk pembangunan perangkat lunak yang dibangun dengan menggunakan teknik pemrograman berorientasi objek.

UML merupakan bahasa visual untuk permodelan dan komunikasi mengenai sebuah sistem dengan menggunakan diagram dan teks-teks pendukung. Diagram berbentuk grafik yang menunjukkan simbol elemen model yang disusun untuk mengilustrasikan bagian atau aspek tertentu dari sistem. Sebuah diagram merupakan bagian dari suatu view tertentu dan ketika digambarkan biasanya dialokasikan untuk view tertentu. Adapun jenis diagram antara lain :

\section{Use Case Diagram}

Menurut Sukamto dan Shalahuddin (2013:155) Use case atau diagram use case merupakan permodelan untuk menggambarkan kelakukan (behavior) sistem informasi yang akan dibuat. Use case mendeskripsikan sebuah interaksi antara satu atau lebih aktor dengan sistem informasi yang akan dibuat.

\section{Activity Diagram}

Menurut Sukamto dan Shalahuddin (2013:161) "Diagram aktivitas atau activity diagram menggambarkan workflow (aliran kerja) atau aktivitas dari sebuah sistem atau proses bisnis atau menu yang ada pada perangkat lunak."

\section{Class Diagram}

Menurut Sukamto dan Shalahuddin (2013:141) "Diagram kelas atau class diagram menggambarkan struktur sistem dari segi pendefinisian kelas-kelas yang akan dibuat untuk membangun sistem. Kelas memiliki apa yang disebut atribut dan metode atau operasi."

\section{Sequence Diagram}

Menurut Sukamto dan Shalahuddin (2013:165) Diagram sekuen menggambarkan kelakuan objek pada use case dengan mendeskripsikan waktu hidup objek dan message yang dikirimkan dan diterima antar objek. Oleh karena itu untuk menggambarkan diagram sekuen maka harus diketahui objek-objek yang terlibat dalam sebuah use case beserta metode-metode yang dimiliki kelas yang diinstansiasi menjadi objek itu.

Sukamto dan Shalahuddin (2013:50), menyatakan bahwa Entity Relationship Diagram (ERD) adalah bentuk paling awal dalam melakukan perancangan basis data relasional. 
Permodelan basis data yang paling banyak digunakan adalah Entity Relationship Diagram (ERD). ERD dikembangkan berdasarkan teori himpunan dalam matematika. ERD digunakan untuk permodelan basis data relasional.

Komponen-komponen ERD yaitu terdiri dari :

1. Entitas (Entity) adalah suatu objek yang dapat diidentifikasi dalam lingkungan pemakai.

2. Relasi (Relationship) menunjukkan adanya hubungan di antara sejumlah entitas yang berbeda.

3. Atribut (Attribute) adalah bagian yang berfungsi mendeskripsikan karakter entitas.

4. Kardinalitas (Cardinality) menunjukkan jumlah maksimum entitas yang dapat berelasi dengan entitas pada himpunan entitas lain.

5. Modalitas (Modality) adalah partisipasi sebuah entitas pada suatu relasi.

Website adalah sejumlah halaman web yang memiliki topik saling terkait, terkadang disertai pula dengan berkas-berkas gambar, video, atau jenis-jenis berkas lainnya.

Supono dan Putratama (2016:109) mendefinisikan CodeIgniter sebagai "Aplikasi open source berupa framework dengan model MVC (Model, View, Controller) untuk membangun website dinamis dengan menggunakan PHP”

Menurut Abdulloh (2016:157) Bootstrap merupakan salah satu framework CSS yang sangat populer di kalangan pecinta pemrograman website. Dengan menggunakan bootstrap, proses desain website tidak dibuat dari nol, sehingga proses desain website lebih cepat dan mudah.

Menuruti Iskandar (2009:1) Internet atau interconnected network adalah sebuah sistem komunikasi global yang menghubungkan komputer-komputer dan jaringan secara langsung maupun tidak langsung ke beberapa jalur utama yang disebut internet backbone. Masingmasing dibedakan anatar satu dengan yang lainnya menggunakan unique name yang disebut alamat 32 bit. Contoh alamat ip adalah 202.155.4.230. Komputer dan jaringan dengan berbagai platform (unix, linux, windows, mac, dan lain lain, masing-masing mempunyai perbedaan dan ciri khas) dapat bertukar informasi dengan adanya sebuah protocol standar yang dikenal dengan nama TCP/IP (Transmission Control Protocol / Internet Protocol). TCP/IP tersusun atas empat layer, yaitu network access, internet, hostto-host transport dan application. Setiap layer tersebut memliki protokolnya masingmasing.

PHP adalah salah satu bahasa pemrograman script yang dirancang untuk membangun aplikasi web. Ketika dipanggil dari web browser, program yang ditulis dengan PHP akan 
di-parsing di dalam web server oleh interpreter PHP dan diterjemahkan kedalam dokumen HTML, yang selanjutnya akan ditampilkan kembali ke web browser. Karena pemrosesan program PHP dilakukan di lingkungan web server, PHP dikatakan sebagai bahasa sisi server (server-side). (Samudera, 2015).

Menurut Faizal dan Irnawati (2015:4) mendefinisikan MySQL merupakan perangkat lunak sistem manajemen basis data (bahasa Inggris : database management system) atau DBMS yang multithread dan multi-user, dengan sekitar 6 (enam) juta instalasi di seluruh dunia.

Pemrograman PHP juga sangat mendukung database MySQL. MySQL adalah Relational Database Management System (RDBMS) yang didistribusikan secara gratis dibawah lisensi GPL (General Public License). Dimana setiap orang bebas untuk menggunakan MySQL, namun tidak boleh dijadikan produk turunan yang bersifat komersial. MySQL sebenarnya merupakan turunan salah satu konsep utama dalam database sejak lama, yaitu SQL (Structured Query Language). SQL adalah sebuah konsep pengoperasian database, terutama untuk pemilihan atau seleksi dan pemasukan data, yang memungkinkan pengoperasian data dikerjakan dengan mudah secara otomatis. Keandalan suatu database (DBMS) dapat diketahui dari cara kerja optimizer-nya dalam melakukan proses perintahperintah SQL, yang dibuat oleh user maupun program-program aplikasinya. Sebagai database server, MySQL dapat dikatakan lebih unggul dibandingkan database server lainnya dalam query data. Hal ini terbukti untuk query yang dilakukan oleh single user, kecepatan query MySQL bisa sepuluh kali lebih cepat dari PostgreSQL dan lima kali lebih cepat dibandingkan Interbase.

Menurut Baskoro (2013:16) Xampp adalah salah satu software server yang bisa berjalan diatas sistem operasi seperti windows, apple, dan linux. Melalui Xampp ini aplikasi website atau CMS bisa dijalankan, termasuk joomla, drupal, wordpress, dan lainnya.

\section{HASIL DAN PEMBAHASAN}

Sistem Informasi Akademik Az Zahra adalah suatu sistem yang dirancang untuk memudahkan guru, siswa khususnya bagian admin dalam mengelola aktifitas belajar dan aktifitas sekolah lainnya. Sistem ini juga mencakup informasi-informasi yang berkaitan dengan jadwal sekolah yang dapat diakses oleh siswa. Berikut ini spesifikasi kebutuhan (system requirement) dari sistem informasi akademik yayasan zahra :

Halaman Admin:

A1. ADMIN dapat melakukan login

A2. ADMIN dapat mengelola data user

A3. ADMIN dapat melihat laporan kartu rencana studi 
A4. ADMIN dapat melihat laporan kartu hasil studi

A5. ADMIN dapat melihat laporan jadwal kuliah

Halaman Guru:

B1. Guru dapat melakukan Login

B2. Guru dapat melihat jadwal mengajar

B3. Guru dapat mengelola absen

B4. Guru dapat mengelola nilai

B5. Guru dapat melihat biodata pribadi

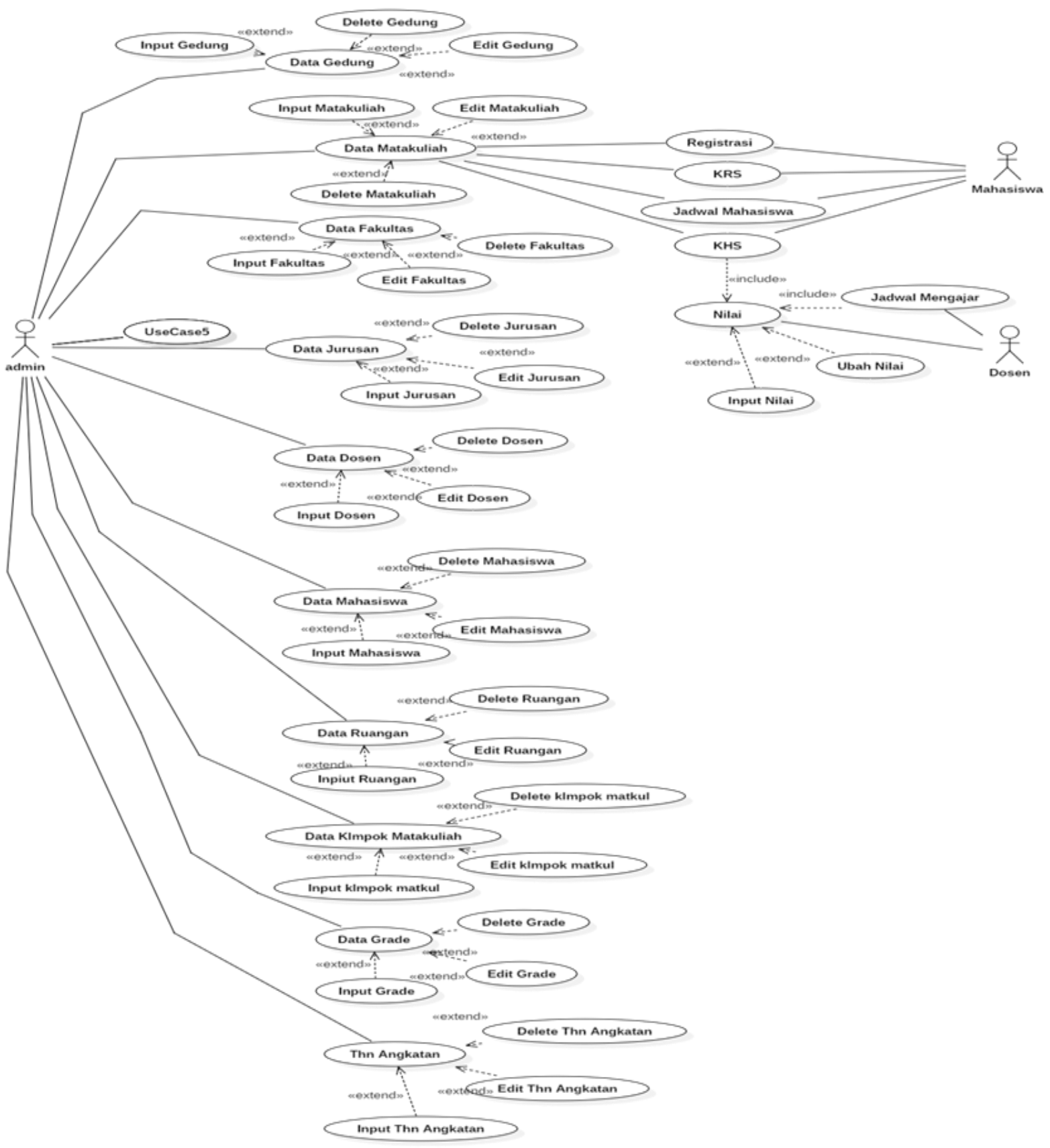

Gambar 1. Use Case Diagram 


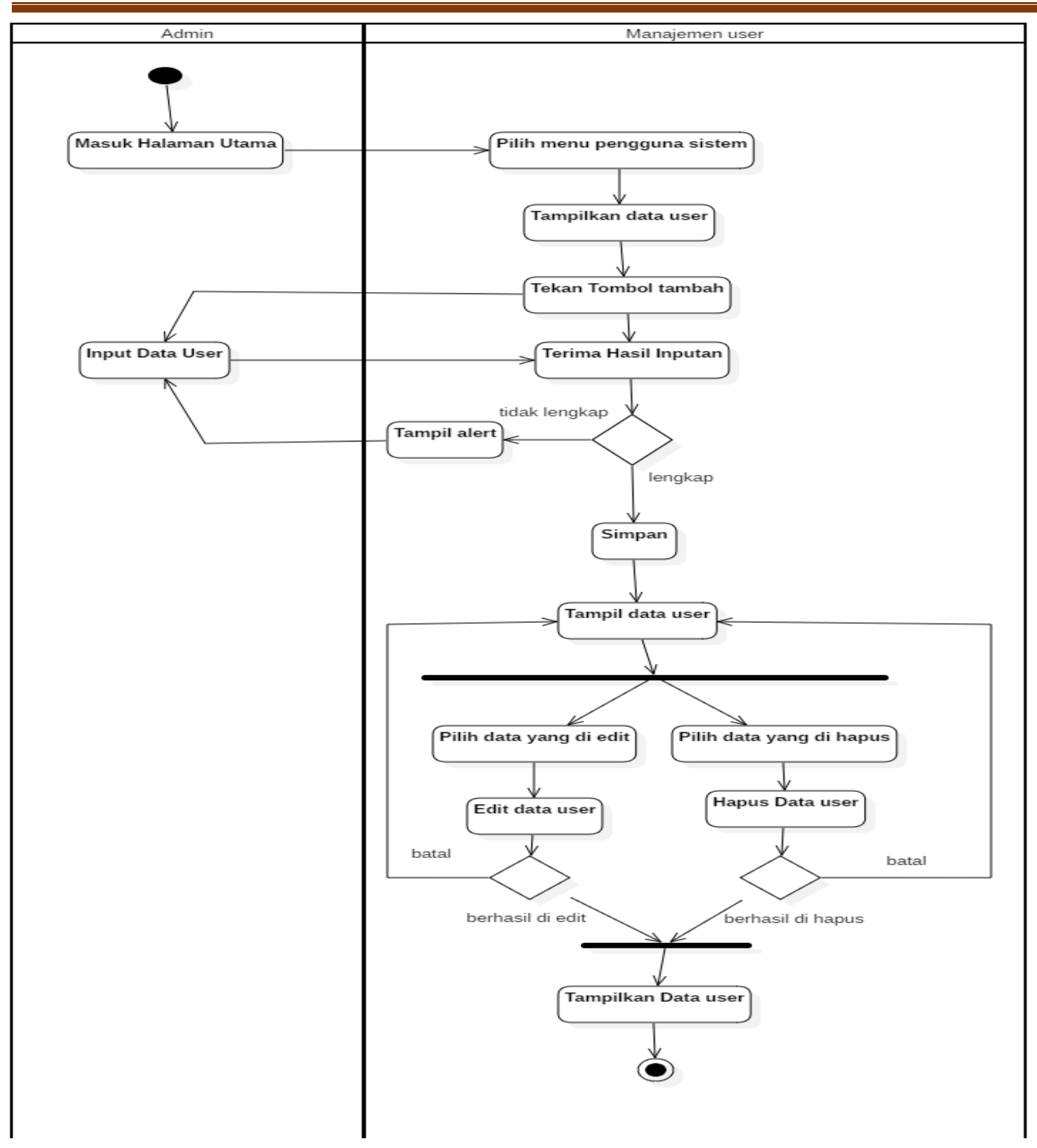

Gambar 2. Activity Diagram Manajemen Data User 


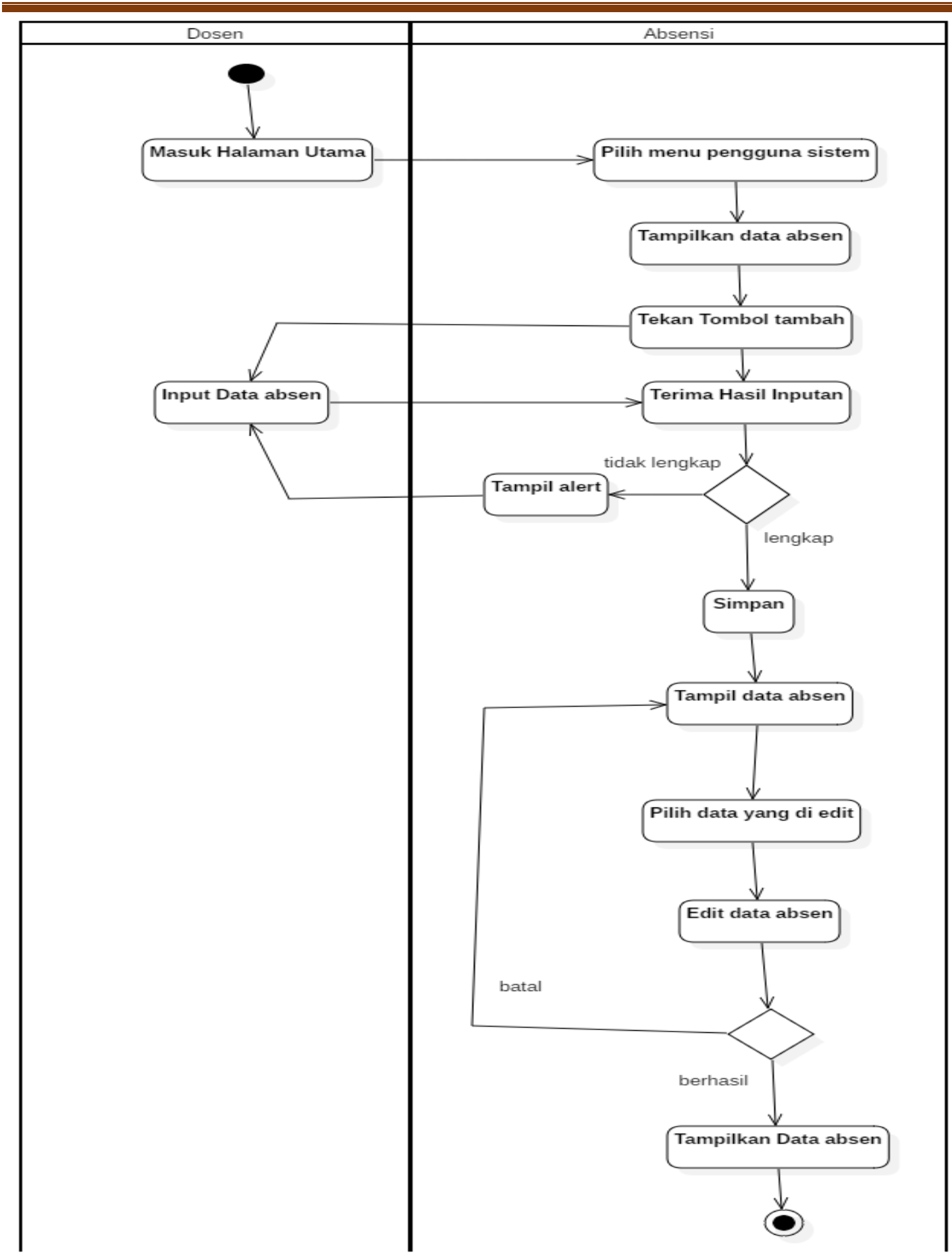

Gambar 3. Activity Diagram Guru Mengelola Absen 


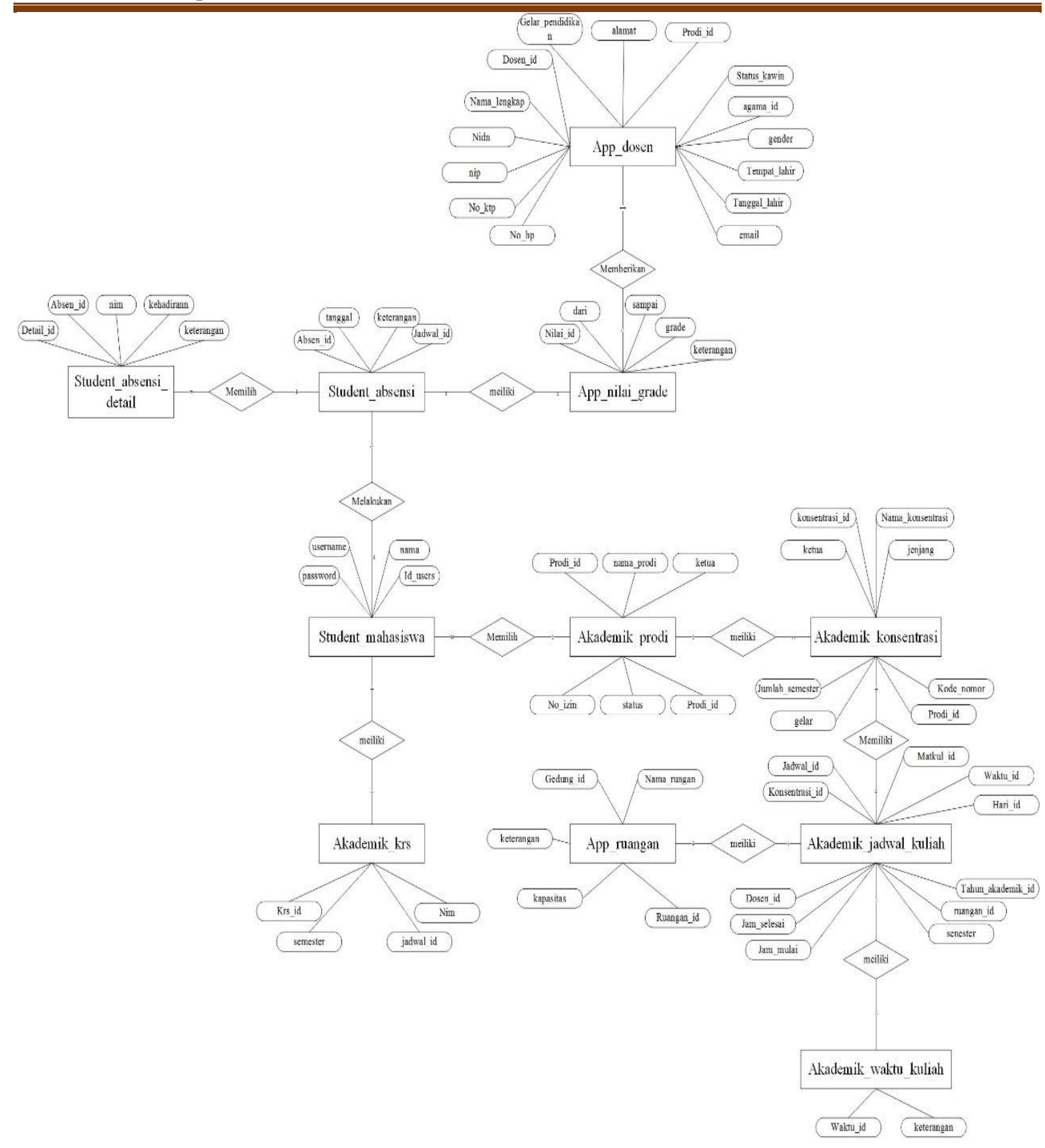

Gambar 4. Entity Relationship Diagram 


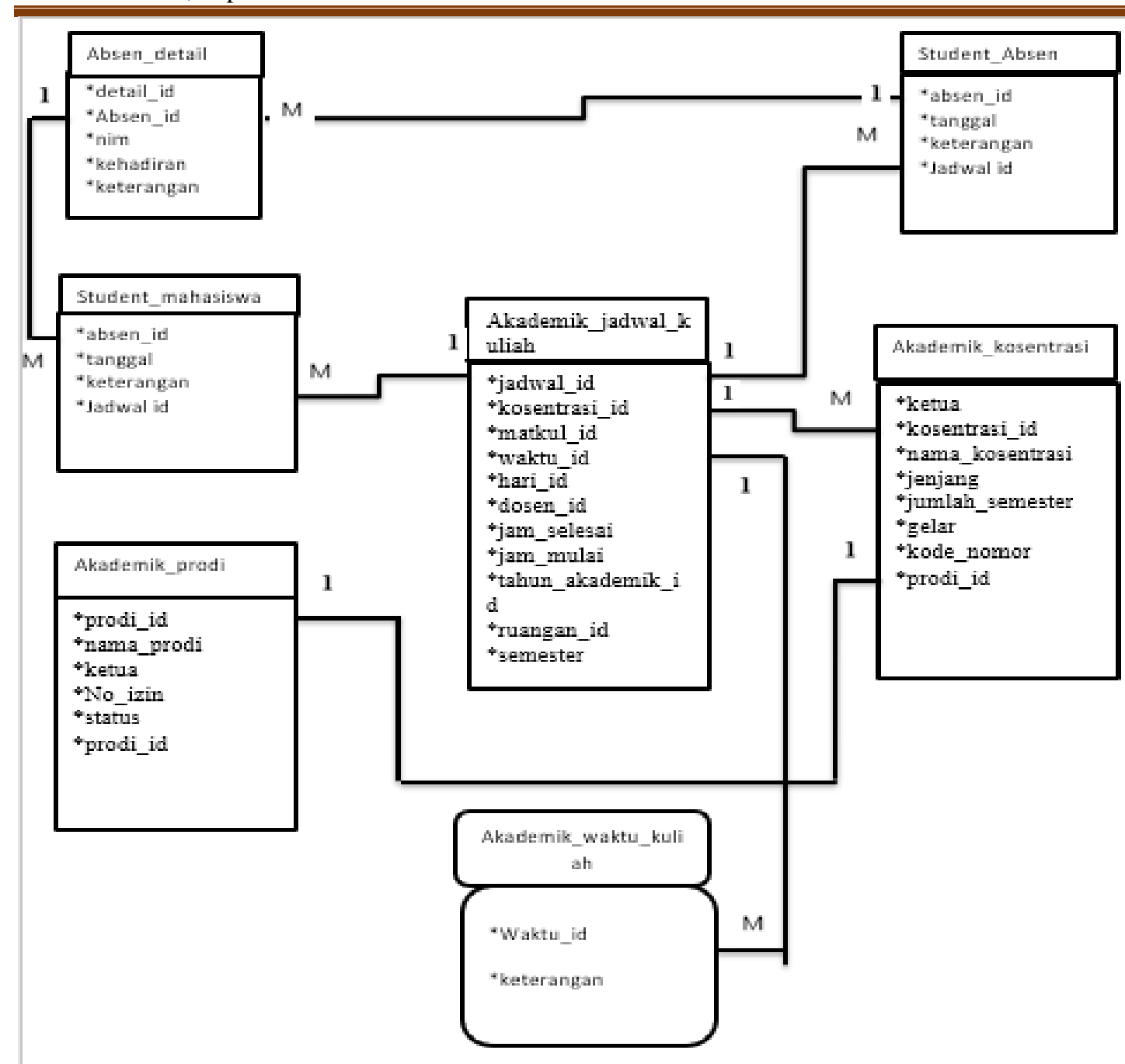

Gambar 5. Logical Record Structure

Rancangan layar atau user interface merupakan salah satu komponen dari sistem yang berfungsi sebagai sarana komunikasi antara user (siswa), guru dengan program sistem yang digunakan.

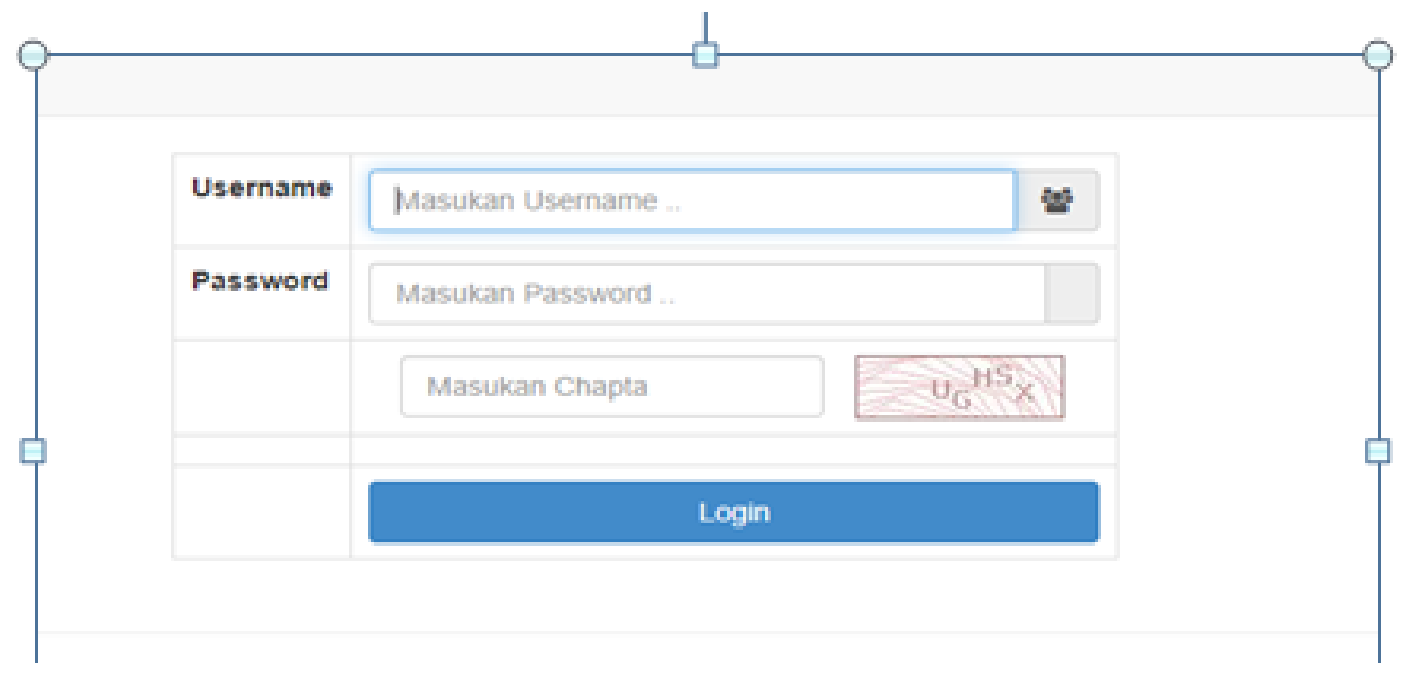

Gambar 6. Halaman Login 


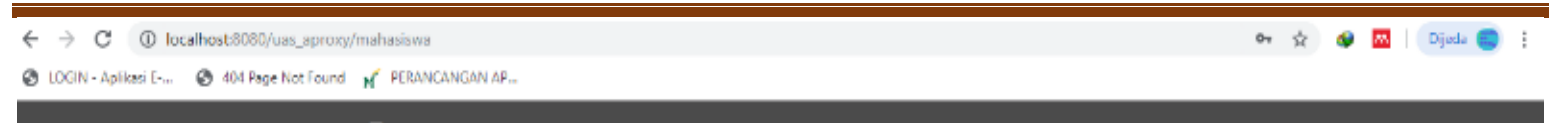

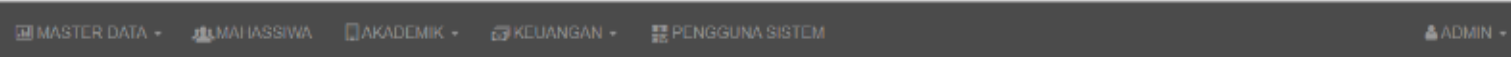

Daftar Mahasiswa

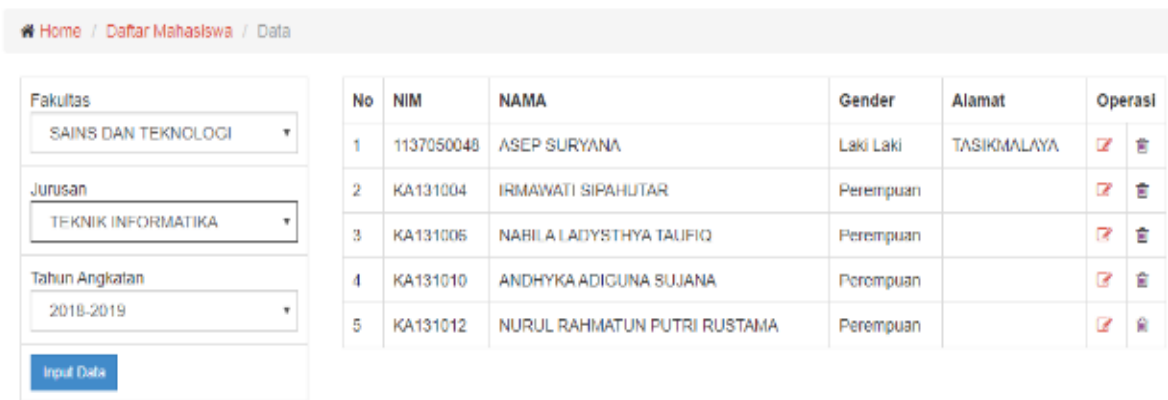

6sistem Informasi Akademik Kampus

Gambar 7. Halaman Daftar Siswa

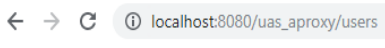

Users

* Home / Users / Entry Record

\section{Tambah Data}

10 .

\begin{tabular}{|c|c|c|c|c|c|c|}
\hline & No & Username & 4 & Level $\neq$ & Last Login & Keterangan \\
\hline $1 \times$ & 1 & admin & & Admin & 18 Desember 2019 & \\
\hline $1 x$ & 2 & usuludin & & Jurusan & 29 November 2019 & Usuludin \\
\hline \& $x$ & 3 & asep & & Dosen & 05 Desember 2019 & asep suryana \\
\hline ax & 4 & admin & & Dosen & 18 Desember 2019 & sample dosen \\
\hline / $x$ & 5 & fisip & & Jurusan & 04 Desember 2019 & Fisip \\
\hline $1 x$ & 6 & saintek & & Jurusan & 04 Desember 2019 & Sains dan Teknologi \\
\hline - $x$ & 7 & mahasiswa & & & 17 Desember 2019 & \\
\hline $1 x$ & 8 & dosen & & Dosen & 17 Desember 2019 & Agustinus \\
\hline
\end{tabular}

Gambar 8. Halaman Manajemen User

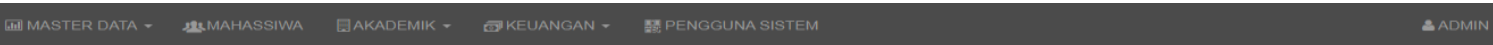

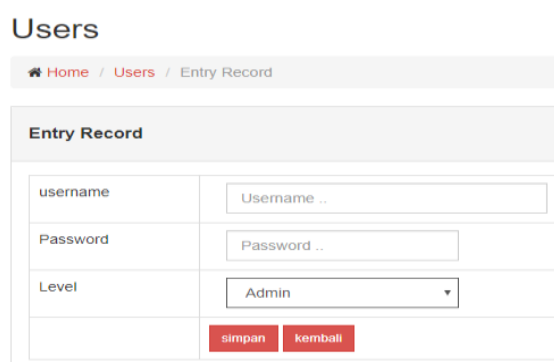


Jadwal Mengajar

\begin{tabular}{|c|c|c|c|c|c|c|c|c|}
\hline \multicolumn{2}{|c|}{ Nama Dosen } & \multicolumn{7}{|l|}{ :Agustinus } \\
\hline \multicolumn{2}{|c|}{ Tahun Akdemik } & \multicolumn{7}{|l|}{ : 2019-2020 } \\
\hline \multicolumn{9}{|c|}{ Jadwal Mengajar } \\
\hline No & \multicolumn{2}{|l|}{ Jurusan } & Kode & Matakuliah & Hari & Ruangan & Jam & sks \\
\hline 1 & \multicolumn{2}{|c|}{ S1 - TEKNIK INFORMATIKA } & DTIKB012 & PRAKTEK KONSEP PEMROGRAMAN & RABU & NOT SET & $08: 00-11: 20$ & $4 \mathrm{SKS}$ \\
\hline 2 & \multicolumn{2}{|c|}{ S1 - TEKNIK INFORMATIKA } & DTIKB02 & SISTEM OPERASI 1 & SENIN & L1.R06 & $13: 00-16: 20$ & 4 SKS \\
\hline 3 & \multicolumn{2}{|c|}{ S1 - TEKNIK INFORMATIKA } & DTIKB07 & KOMUNIKASI DATA & NOT SET & NOT SET & - & $4 \mathrm{SKS}$ \\
\hline 4 & \multicolumn{2}{|c|}{ S1 - TEKNIK INFORMATIKA } & DTIKB11 & ARSITEKTUR KOMPUTER 1 & NOT SET & NOT SET & - & $4 \mathrm{SKS}$ \\
\hline
\end{tabular}

Gambar 10. Halaman Jadwal

\section{首JADWAL 自ABSENMAHASISWA 扈NIIAI \& BODATA}

Absen

* Home / Absen / Data

\begin{tabular}{|l|}
\hline Kelas Anda \\
\hline Tahun Akademik \\
\hline STRUKTUR DATA \\
\hline $2019-12-18$ \\
\hline Butosave \\
\hline
\end{tabular}

AgustinusSTRUKTUR DATA

MATAKULIAH

Matakuliah STRUKTUR DATA

Dosen Pengapu AGUSTINUS

DATA MAHASISWA

No NIM NAMA MAHASISWA

11137050049 FAJAR BUDIMAN

23E4543 FTRD

1137050046 YAZID

$4 \quad 11035643 \quad$ JOKO PRANOTO

Kehadiran

Gambar 11. Halaman Absen Siswa

\section{兰JADWAL 自ABSENMAHASISWA ER ENILAI 2 BODATA}

Beri Nilai

* Home / Beri Nilai / Data

\begin{tabular}{|l|}
\hline Kelas Ajar \\
\hline Tahun Akademik 2019-2020 \\
\hline STRUKTUR DATA \\
\hline
\end{tabular}

\begin{tabular}{l|l}
\hline MATAKULIAH & \\
\hline Matakuliah & STRUKTUR DATA \\
\hline Dosen Pengapu & AGUSTINUS \\
\hline
\end{tabular}

Dosen Pengapu AGUSTINUS

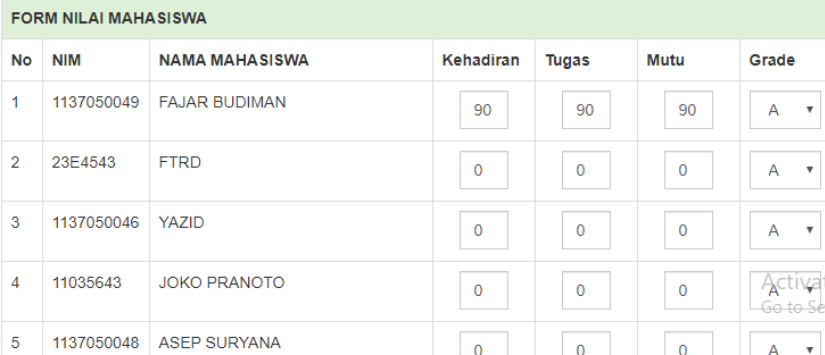

Gambar 12. Halaman Nilai Siswa 


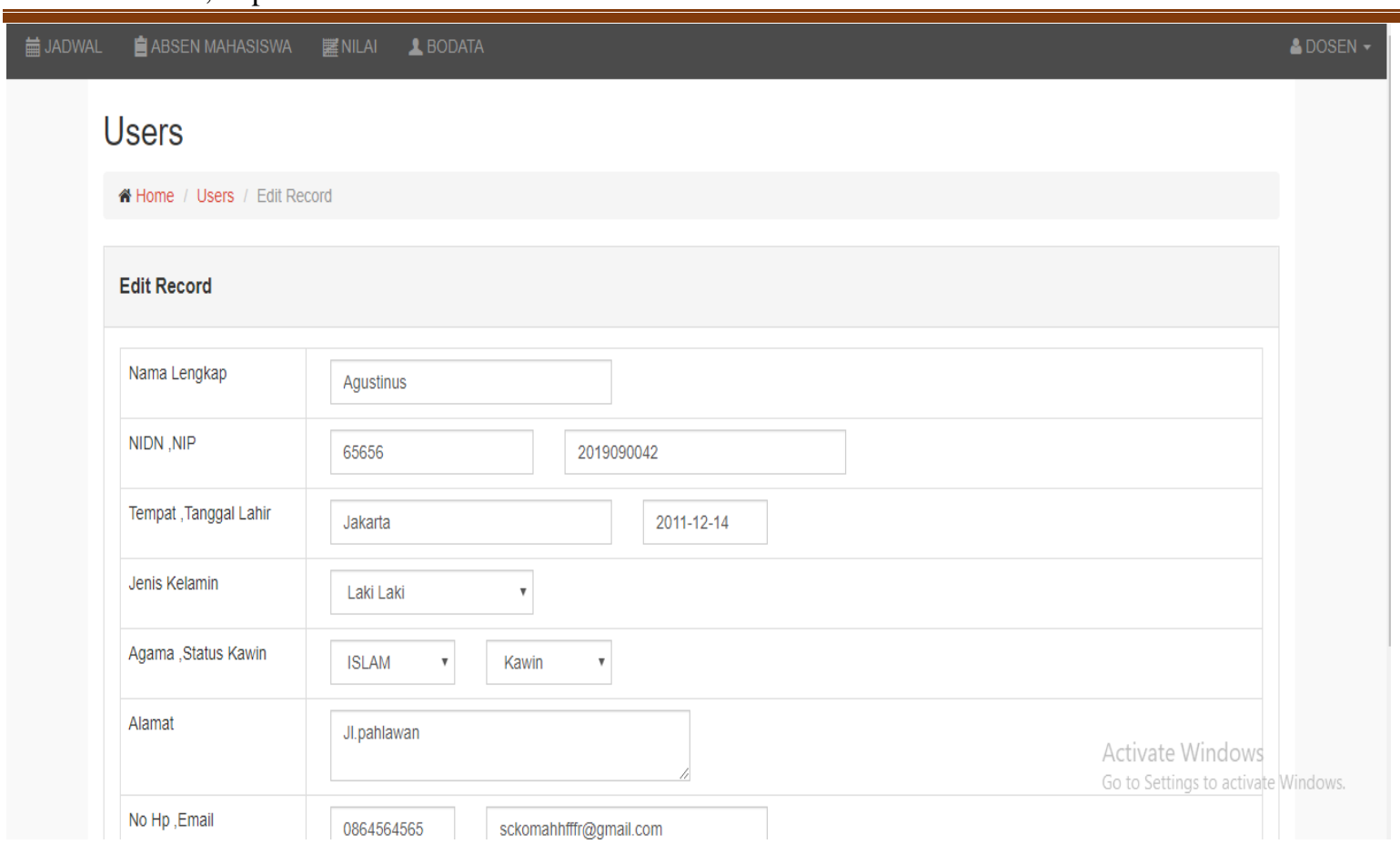

Gambar 13. Halaman Biodata

\section{KESIMPULAN DAN REKOMENDASI}

Berdasarkan hasil pengembangan dari sistem yang telah dilakukan, kesimpulan yang dapat diberikan adalah:

Dengan adanya sistem informasi akademik di yayasan Az Zahra proses penyampaian informasi dari guru ke siswa menjadi lebih cepat dan mudah. Sistem informasi berbasis web pada saat ini memang sudah menjadi kebutuhan yang tidak bisa ditolak. Setelah sistem informasi di implementasi, kegiatan pengolahan data secara manual sudah dapat dialihkan secara online tanpa harus berada disekolah.

Rekomendasi yang perlu dipertimbangakan yaitu:

Perlu diadakannya pelatihan khusus bagi pengguna agar dapat menggunakan sistem informasi dengan baik dan benar. Sistem informasi berbasis web yang telah dibuat hendaknya di maintenance dengan baik dan benar untuk mencapai tujuan yang diharapkan. Pentingnya backup data dalam database untuk mencegah hal hal yang tidak diinginkan.

\section{REFERENSI}

Anggraeni, E. Y., \& Irviani, R. (2017). Pengantar Sistem Informasi. (E. Risanto, Ed.).Yogyakarta: Penerbit

Andi.Bakhri, S. (2015). Rancang Bangun Sistem Informasi Penjualan Sembako Menggunakan Metode Waterfall, 3(1), 70-82. 
Hery. (2012). Pengantar Akuntansi 1. Jakarta: Fakultas Ekonomi Universitas Indonesia.

Muslihudin, M., \& Oktafianto. (2016). Analisis dan Perancangan Sistem Informasi Menggunakan Model Terstruktur dan UML. (A. Pramesta, Ed.). Yogyakarta: Penerbit Andi.

Puspitasari, D. (2015). Rancang Bangun Sistem Informasi Koperasi Simpan Pinjam Karyawan Berbasis Web. Seminar Nasional Ilmu Pengetahuan Dan Teknologi Komputer, XI(2), 186-INF.196.

Rahmawati, M. (2015). Peran Aplikasi Komputer Berbasis Akuntansi untuk Badan Usaha Dalam Persfektif Sistem Informasi, XIII(2), 172-183.

Ramanda, K., Rusman, A., \& Agustin, R. (2017). Rancang Bangun Sistem Informasi Service Center Pada PT . Catur Sukses Internasional Jakarta, 7(2), $1-5$.

Rosa, A. S., \& Shalahuddin, M. (2016). Rekayasa Perangkat Lunak Terstruktur dan Berbasis (Puspitasari, 2015)Objek. Bandung: Informatika.

Syahputra, R., \& Amin, S. (2016). IOS Visual Programming. Yogyakarta: Mediakom. 